\title{
A new SPECT/CT reconstruction algorithm: reliability and accuracy in clinical routine for non-oncologic bone diseases
}

\author{
Olivier Delcroix ${ }^{1}$, Philippe Robin 1,3,4, Maelenn Gouillou², Alexandra Le Duc-Pennec', Zarrin Alavi ${ }^{5}$, \\ Pierre-Yves Le Roux ${ }^{1,3,4}$, Ronan Abgral ${ }^{1,3,4}$, Pierre-Yves Salaun ${ }^{1,3,4}$, David Bourhis ${ }^{1,3,4}$ and Solène Querellou ${ }^{1,3,4,6^{*}}$ (i)
}

\begin{abstract}
Background: $x$ SPECT Bone ${ }^{\oplus}(x B)$ is a new reconstruction algorithm developed by Siemens ${ }^{\circledast}$ in bone hybrid imaging (SPECT/CT). A CT-based tissue segmentation is incorporated into SPECT reconstruction to provide SPECT images with bone anatomy appearance. The objectives of this study were to assess XB/CT reconstruction diagnostic reliability and accuracy in comparison with Flash $3 \mathrm{D}^{\circledast}$ (F3D)/CT in clinical routine. Two hundred thirteen consecutive patients referred to the Brest Nuclear Medicine Department for non-oncological bone diseases were evaluated retrospectively. Two hundred seven SPECT/CT were included. All SPECT/CT were independently interpreted by two nuclear medicine physicians (a junior and a senior expert) with $\times B / C T$ then with F3D/CT three months later. Interobserver agreement (IOA) and diagnostic confidence were determined using McNemar test, and unweighted Kappa coefficient. The study objectives were then re-assessed for validation through $>18$ months of clinical and paraclinical follow-up.
\end{abstract}

Results: No statistically significant differences between IOA $\times B$ and IOA F3D were found $(p=0.532)$. Agreement for xB after categorical classification of the diagnoses was high ( $\kappa_{x \mathrm{~B}}=0.89$ [95\% Cl $\left.0.84-0.93\right]$ ) but without statistically significant difference F3D ( $K_{\text {F3D }}=0.90[95 \% \mathrm{Cl} 0.86-0.94]$ ). Thirty-one $(14.9 \%)$ inter-reconstruction diagnostic discrepancies were observed of which 21 (10.1\%) were classified as major. The follow-up confirmed the diagnosis of F3D in 10 cases, XB in 6 cases and was non-contributory in 5 cases.

Conclusions: $\times B$ reconstruction algorithm was found reliable, providing high interobserver agreement and similar diagnostic confidence to F3D reconstruction in clinical routine.

Keywords: SPECT/CT, Bone diseases, Diagnostic accuracy, Scintigraphy, xSPECT Bone ${ }^{\oplus}$, Reconstruction algorithm

\section{Background}

$\mathrm{xSPECT}^{\mathrm{B}} \mathrm{B}^{\circ}(\mathrm{xB})$ is a new iterative reconstruction algorithm developed by Siemens ${ }^{\circ}$ for bone single photon emission computed tomography (SPECT). Unlike classic SPECT reconstructions, $\mathrm{xB}$ uses ordered subset conjugate gradient minimization algorithm (OSCGM). Its originality consists of constraining counts in computed tomography (CT) based on bone segmentation (Fig. 1) and providing a quantitative reconstruction $[1,2]$.

\footnotetext{
* Correspondence: solene.querellou@chu-brest.fr

${ }^{1}$ Nuclear Medicine Department, CHRU Hospital Morvan, Brest, France

${ }^{3}$ Service de Médecine Nucléaire, EA 3878 GETBO IFR 148, Brest, France

Full list of author information is available at the end of the article
}

This innovation, like the progress of image acquisition and reconstruction, could convey a higher diagnostic confidence through an enhanced bone uptake location. Studies have reported early planar images with good sensitivity yet poor specificity. The latter was improved when using SPECT reconstructions with negative predictive value while maintaining an excellent sensitivity [3-5]. Moreover, the use of CT improved the specificity of SPECT [4], particularly concerning small lesions. Besides, physical limitations such as attenuation or Compton scattering have also benefited from corrections integrated directly into reconstruction algorithms, leading to less artifacts and shorter reconstruction time. Then, the "side-by-side" display of SPECT and CT 


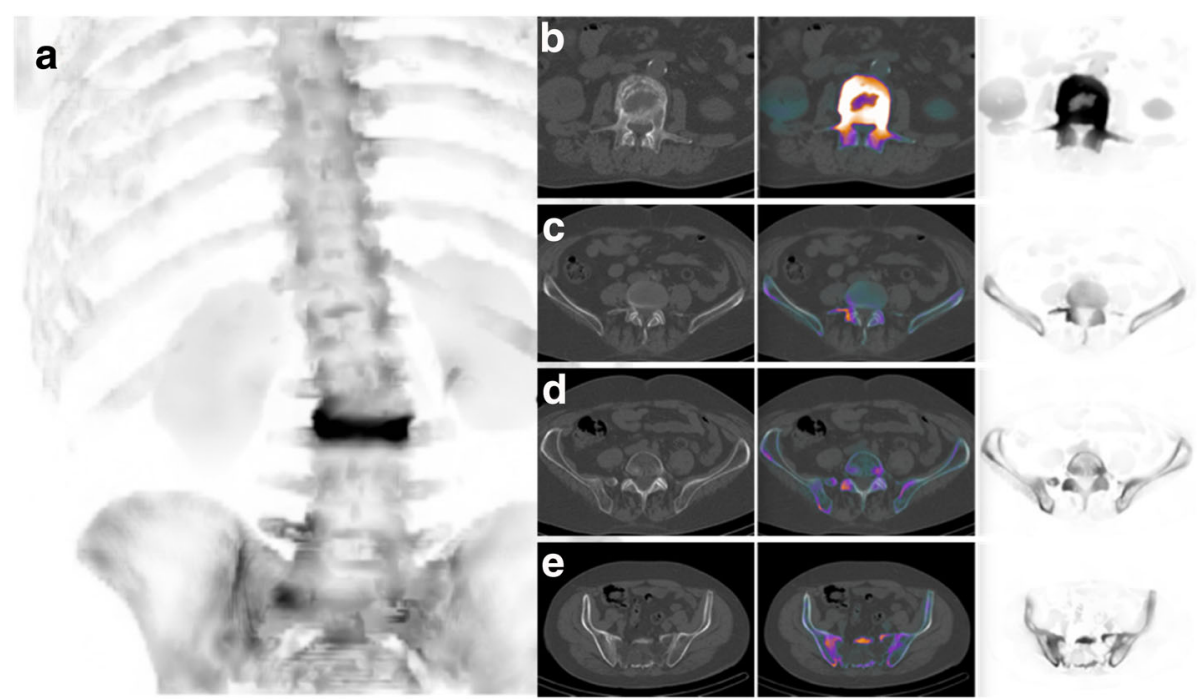

Fig. 1 Example of an xSPECT Bone reconstruction providing SPECT images with bone anatomy appearance. The xSPECT Bone ${ }^{\circledR}$ maximum intensity projections (MIP) combines scintigraphic data with morphological data from the computed tomography. In this example, the scintigraphy was performed in order to explore an acute low back pain. The exclusive use of the XSPECT Bone ${ }^{\circledast}$ MIP (a) makes it possible to visualize on one image an uptake related to a fracture of a vertebral body responsible for spinal angulation, to identify the vertebra concerned (L3), to visualize an uptake localized on the fifth right transverse process extended to the zygapophysial joint, and to visualize an uptake of the last right zygapophysial joint and an uptake asymmetry of the sacroiliac joints. Transaxial image analysis confirms the fracture of the L3 vertebral body (b) and specifies its extension toward the pedicles. It also confirms the uptake of the fifth right transverse process (c), of the last right zygapophysial joint (d) and the uptake asymmetry of the sacroiliac joints (e)

images $(\mathrm{SPECT}+\mathrm{CT})$ was replaced by fused SPECT/CT images [6-10]. In this manner, Römer et al. were able to identify $90 \%$ of SPECT findings classified as indeterminate [11]. These authors also indicated that exact matching of functional and anatomic data may be necessary, especially for imaging of small anatomic structures.

That said, taking into account patient's clinical data should also be regarded as a mainstay in enhancement of overall diagnostic confidence of scintigraphy.

In the end, in non-oncological context, the objective of both clinician and health care provider is to reduce additional imaging that could delay patient management, increase stress, and induce additional irradiation.

The objectives of this study were:

- First, to evaluate the reliability of $\mathrm{xB} / \mathrm{CT}$ bone reconstruction in comparison with that of Flash $3 \mathrm{D}^{\circ}$ (F3D)/CT.

- Second, to evaluate the diagnostic confidence of $\mathrm{xB} /$ CT compared with that of F3D/CT for nononcological painful bone diseases according to the recommendations of good practice of the European Association of Nuclear Medicine [12].

\section{Methods}

\section{Patients}

A retrospective study was conducted on 213 nononcological patients referred for a bone scintigraphy at the Nuclear Medicine Department of Brest University Hospital from March to September 2014. Seven patients were excluded (four due to a poor image fusion between SPECT and CT related to important movements, one for whom the SPECT/CT was not retrieved from PACS (picture archiving and communication system), another for whom the field of view of the CT was too small, and finally one who declined to participate in the study). All patients were given verbal information before the exams that their data could be used for future scientific research and gave their written consent.

The SPECT/CT of 206 patients was analyzed (70 male and 136 female) with 13 patients younger than 18 years old. Their mean age \pm SD was $53.2 \pm 18.8$.

Two hundred seven SPECT/CT were included for 206 patients (2 SPECT/CT performed for the same patient). The anatomical areas explored are summarized in Table 1.

\section{Imaging acquisition}

SPECT/CT data were acquired between 2 and $4 \mathrm{~h}$ after the intravenous injection of approximately $9 \mathrm{MBq} / \mathrm{kg}$ of ${ }^{99}{ }^{\mathrm{m}} \mathrm{TcDPD}$ (TECEOS ${ }^{\circ}$, CIS bio-international, 91112 Gif-Sur-Yvette, France) on a Symbia Intevo T6 dualheaded gamma camera (Siemens ${ }^{\circ}$ SAS Medical Solutions, Munich, Germany) equipped with a lowenergy high-resolution parallel-hole collimator. The energy window was set at $15 \%$, centered on the photon energy peak of ${ }^{99 \mathrm{~m}} \mathrm{Tc}(140 \mathrm{keV})$. 
Table 1 Anatomical areas explored

\begin{tabular}{ll}
\hline SPECT/CT & 207 \\
\hline Hip and pelvis & 32 \\
Elbow & 1 \\
Shoulder & 8 \\
Knee & 20 \\
Hand-wrist & 25 \\
Foot-ankle & 101 \\
Spine & 11 \\
Tibia & 1 \\
Chest & 8 \\
\hline
\end{tabular}

The SPECT acquisition protocol was as follows: 60 frames per detector head, each with duration of $10 \mathrm{~s}$, were acquired in step-and-shoot mode over $360^{\circ}$ with non-circular orbit. Acquisition matrix was $256 \times 256$ to allow $\mathrm{xB}$ reconstruction.

The CT acquisition was performed immediately after the SPECT acquisition as follows: the image matrix size was $512 \times 512$, with a tube voltage of $110 \mathrm{kV}$ for the extremities and $130 \mathrm{kV}$ out of the extremities; automatic exposure control system (CARE Dose4D) with 90 quality reference mAs; a pitch of 1.05 for the extremities and 1.0 out of the extremities; a slice thickness of $5 \mathrm{~mm}$ for attenuation correction (AC), $1.25 \mathrm{~mm}$ for the extremities, and $3 \mathrm{~mm}$ out of the extremities; and a field of view of $30 \mathrm{~cm}$ for the extremities and $50 \mathrm{~cm}$ out of the extremities including the knees. FBP reconstructions were used with a B31s filter for AC, IRIS iterative reconstructions with i30s and i80s filters for analysis.

The SPECT/CT acquisition for the wrist and hand was performed on prone position.

\section{Reconstructions $\mathrm{XB}$ and F3D}

The goal of iterative reconstruction is to find the best estimated slice that, when projected in multiple directions, is as close to acquired projections as possible. $\mathrm{xSPECT}$ is based on OSCGM algorithm, and $\mathrm{xB}$ is a variant of $\mathrm{xSPECT}^{\circ}$ that considers that almost all the ${ }^{99 \mathrm{~m}} \mathrm{Tc}-\mathrm{DPD}$ is localized in bones. First, CT is re-sampled to $\mathrm{xSPECT}^{\circ}$ resolution $\left(256^{2}\right)$. CT data are then segmented in five increasing DPD uptake probability areas (air, adipose tissue, soft tissue, spongy bone, cortical bone). Those probabilities are incorporated in the $\mathrm{xB}$ algorithm, which constrains the reconstructed data in high uptake probability area, especially bones. To speed up the computation, ordered subsets can also be used [1].

The $\mathrm{xB}$ reconstruction was first performed with 36 iterations and 1 subset, a $256 \times 256$ matrix that leads to a 2.4-mm pixel and a $10-\mathrm{mm}$ full width at the half maximum (FWHM) Gaussian post-filter. Then, an undersampling from $256^{2}$ to $128^{2}$ was performed on the projections in order to perform F3D reconstruction, with 8 iterations, 15 subsets, and a 12-mm FWHM Gaussian post-filter.

\section{Image analysis}

Co-registered CT, SPECT, and SPECT/CT images were visualized with a commercially available $3 \mathrm{D}$ volume fusion tool (Syngo.via ${ }^{\circ}$, Siemens Healthcare). The 3D images were displayed as 2D orthogonal (axial, coronal, and sagittal, automatically generated by multiplanar reformatting (MPR) from the axial slices) and maximum intensity projections (MIP) on two screens through a custom display, allowing spatial synchronization through a triangulation pattern. The look-up table of the SPECT/ CT images was "Warm Metal."

\section{Interpretation and analysis of data}

Retrospectively, all bone scans were independently interpreted by two nuclear medicine physicians (one senior physician (experience of 15 years) and one junior physician (experience of 3 years)) with the $\mathrm{xB} / \mathrm{CT}$ reconstruction and then 3 months later in order to obtain a blind interpretation of the first one with F3D/CT reconstruction. Choosing a junior and a senior physician would allow assessment of the diagnostic confidence reliability and accuracy in bone reconstruction, whatever the reader's experiences. Each bone scintigraphy was interpreted by simultaneous analysis of the SPECT, CT, and SPECT/CT reconstructions. The interpretation was made with the knowledge of the clinical context, i.e., our clinical routine.

The diagnoses were classified into five categories: 1-normal scintigraphy, 2-arthritis, 3-periarticular disease, 4-fracture or tumor pathology, and 5-complex regional pain syndrome. The diagnoses are summarized in Table 2.

First, the interpretation discrepancies between the two physicians were identified within $\mathrm{xB}$ and within F3D. In case of diagnostic discrepancy between the two physicians, the diagnosis was made after consensus. In a second step, the diagnostic differences between $\mathrm{xB}$ and $\mathrm{F} 3 \mathrm{D}$ reconstructions after harmonization within each reconstruction were identified. They were classified as major (if the diagnosis and the treatment were different) or minor (if they were irrelevant and did not lead to any therapeutic modification).

\section{Clinical and paraclinical follow-up}

For all included patients, the follow-up was carried out either by consulting the medical file or by calling the referring physician and/or the patient directly. Due to the retrospective nature of our study, the referring physician had already received the F3D reconstruction report. The 
Table 2 Categorical classification of the diagnosis

\begin{tabular}{|c|c|c|}
\hline 1 & Normal scintigraphy & $\begin{array}{l}\text { No pathological uptake } \\
\text { CT anomaly without uptake on } \\
\text { the SPECT } \\
\text { Non-pathological bone remodeling, } \\
\text { after surgery for instance }\end{array}$ \\
\hline 2 & Articular disease & $\begin{array}{l}\text { Arthrosis } \\
\text { Os trigonum syndrome } \\
\text { Sacroiliitis } \\
\text { Infectious arthritis } \\
\text { Joint manifestation of alkaptonuria } \\
\text { Prosthesis failure } \\
\text { Stress shielding } \\
\text { Bone-prosthesis conflict }\end{array}$ \\
\hline 3 & Periarticular disease & $\begin{array}{l}\text { Heel spur } \\
\text { Rheumatic disease } \\
\text { Plantar fasciitis } \\
\text { Para-osteo-arthropathy }\end{array}$ \\
\hline 4 & $\begin{array}{l}\text { Fracture or tumor } \\
\text { pathology }\end{array}$ & $\begin{array}{l}\text { Fracture } \\
\text { Osteochondral lesion of the talar dom } \\
\text { Micro fracture } \\
\text { Pseudarthrosis } \\
\text { Fibrous dysplasia of bone } \\
\text { Osteitis } \\
\text { Osteoid osteoma } \\
\text { Osteonecrosis }\end{array}$ \\
\hline 5 & $\begin{array}{l}\text { Complex regional } \\
\text { pain syndrome }\end{array}$ & Complex regional pain syndrome \\
\hline
\end{tabular}

clinical and paraclinical follow-up was carried out over 18 months after scintigraphy of the last patient. Of the 206 patients, 204 were followed up. Two patients were lost to follow-up. Patients' additional data are summarized in Table 3.

The diagnostic differences (major or minor) between $\mathrm{xB}$ and $\mathrm{F} 3 \mathrm{D}$ reconstructions were compared with the clinical and paraclinical follow-up, considered as the reference standard in our study.

\section{Statistical analysis}

The comparison of the IOA by reconstruction was performed according to two distinct statistical methods: raw diagnoses were compared with a McNemar test and diagnostic categories were compared with an

Table 3 Clinical and paraclinical follow-up

\begin{tabular}{ll}
\hline Plain radiograph & 104 \\
Magnetic resonance imaging & 45 \\
Computed tomography (CT) & 34 \\
CT arthrography & 9 \\
Ultrasound & 25 \\
Electromyography & 2 \\
New bone SPECT/CT & 15 \\
Bacteriological analysis & 3 \\
Clinical follow-up alone & 47 \\
\hline
\end{tabular}

Table 4 Inter-observer agreement between xSPECT Bone ${ }^{\circledR}$ and Flash 3D ${ }^{\circledR}$ reconstruction algorithms

\begin{tabular}{lll}
\hline XSPECT Bone $^{\oplus}$ & Flash 3D $^{\oplus}$ & Discrepancy \\
\cline { 2 - 3 } & Concordant & 23 \\
\hline Concordant & 166 & 0 \\
Discrepancy & 18 &
\end{tabular}

unweighted kappa coefficient (according to the five categories mentioned above).

The retrospective nature of the study did not allow us to have a reference standard independent from the index test. Indeed, for situations in which a difference in diagnosis was observed between $\mathrm{xB}$ and $\mathrm{F} 3 \mathrm{D}$ reconstructions, a simple descriptive comparison with the followup was performed.

\section{Results}

Inter-observer agreement (IOA) and inter-observer discrepancy (IOD)

Among the 207 SPECT/CT interpreted with $\mathrm{xB}$ then with F3D, 23 IOD were observed within F3D without IOD for these same 23 cases with $\mathrm{xB}$, thus representing $11.1 \%$ of IOD in the F3D arm. Similarly, 18 IOD were observed within $\mathrm{xB}$ without IOD for these same 18 cases with $\mathrm{F} 3 \mathrm{D}$, representing $8.7 \%$ of IOD in the $\mathrm{xB}$ group. For the remaining 166 examinations, no IOD was found in both $\mathrm{xB}$ and F3D (Table 4).

A McNemar test showed no statistically significant difference between IOA ${ }_{\mathrm{xB}}$ and IOA F3D $(p=0.532)$.

Moreover, the unweighted kappa coefficient calculated after categorical classification of the diagnoses was high but did not demonstrate a statistically significant difference between F3D and xB: kappa ${ }_{\mathrm{F} 3 \mathrm{D}}=0.90[95 \% \mathrm{CI}$ $0.86-0.94$ ] and kappa ${ }_{x B}=0.89$ [95\% CI 0.84-0.93]. The contingency table of the diagnosis is presented in Table 5, according to the two physicians after categorical classification of the diagnosis.

Table 5 The contingency table of the diagnosis according to the two physicians after categorical classification of the diagnosis (262 lesions were observed for 207 SPECT/CT)

\begin{tabular}{|c|c|c|c|c|c|c|c|c|c|c|}
\hline \multirow{3}{*}{$\begin{array}{l}\text { Physician } 2 \\
\text { Categorical diagnosis }\end{array}$} & \multicolumn{10}{|c|}{ Physician 1} \\
\hline & \multicolumn{5}{|c|}{ Flash 3D } & \multicolumn{5}{|c|}{ xSPECT Bone ${ }^{\oplus}$} \\
\hline & 1 & 2 & 3 & 4 & 5 & 1 & 2 & 3 & 4 & 5 \\
\hline 1 & 62 & 3 & 0 & 2 & 1 & 63 & 7 & 1 & 3 & 1 \\
\hline 2 & 0 & 79 & 0 & 1 & 2 & 0 & 74 & 0 & 2 & 0 \\
\hline 3 & 1 & 0 & 13 & 0 & 0 & 0 & 0 & 13 & 0 & 0 \\
\hline 4 & 4 & 5 & 1 & 57 & 0 & 2 & 4 & 1 & 59 & 1 \\
\hline 5 & 0 & 0 & 0 & 0 & 31 & 0 & 0 & 0 & 0 & 31 \\
\hline
\end{tabular}


Inter-reconstruction diagnostic discrepancy (IRDD)

Thirty-one (14.9\%) IRDD were observed out of 207 SPECT/CT, with raw diagnosis or categorical diagnosis. Twenty-one (10.1\%) IRDD were classified as major and 10 (4.8\%) IRDD as minor.

Among the 21 major IRDD, the follow-up confirmed the diagnosis of F3D in 10 cases and $\mathrm{xB}$ in 6 cases and was non-contributory in 5 cases. Of the 16 cases for which follow-up was informative, there were 5 false negatives for F3D and 4 false negatives for $\mathrm{xB}, 4$ false positives for $\mathrm{xB}$ but none for $\mathrm{F} 3 \mathrm{D}$ and 3 localization errors, 2 for $\mathrm{xB}$ and one for F3D. IRDD are described in Table 6.

\section{IOD-IRDD relations}

Forty-one (19.8\%) IOD were observed for the 207 SPECT/CT. For the 31 IRDD, 13 IOD (41.9\%) were observed. Seven IOD (33.3\%) were observed for the 21 major IRDD, and 6 IOD (60\%) were observed for the 10 minor IRDD.

\section{Analysis of scintigraphy with bone prosthesis}

Twenty-four bone scans concerned an exploration of pain involving joints with prosthetic replacement. Three IOD (12.5\%) were identified (one for $\mathrm{xB}$ and two for F3D). Only one IRDD was identified. Follow-up concluded to a false negative of $x B$. No false positive was identified with $x B$. It

Table 6 Inter-reconstruction diagnostic discrepancy

\begin{tabular}{|c|c|c|c|c|c|}
\hline & Symptoms & xSPECT Bone ${ }^{\circledast}$ abnormalities & Flash 3D ${ }^{\circledR}$ abnormalities & Diagnosis* & Error \\
\hline & \multicolumn{5}{|c|}{ Discrepancy between Flash 3D and diagnosis* } \\
\hline 1 & Hip pain & Right hip uptake & No pathological uptake & Right hip arthrosis & F3D-false negative \\
\hline 2 & Right ankle pain & $\begin{array}{l}\text { Right os trigonum } \\
\text { syndrome }\end{array}$ & Right talus contusion & $\begin{array}{l}\text { Right os trigonum } \\
\text { syndrome }\end{array}$ & F3D-location \\
\hline 3 & Left knee joint pain & $\begin{array}{l}\text { Uptake of fracture } \\
\text { sequelae of patella }\end{array}$ & No pathological uptake & Knee arthritis & F3D-false negative \\
\hline 4 & Left gluteal region pain & Left sacroiliac joint uptake & No pathological uptake & Sacroiliac arthritis & F3D-false negative \\
\hline 5 & $\begin{array}{l}\text { Left knee joint pain, intercondylar } \\
\text { eminence fracture several } \\
\text { months ago }\end{array}$ & $\begin{array}{l}\text { Intercondylar } \\
\text { eminence uptake }\end{array}$ & No pathological uptake & $\begin{array}{l}\text { Intercondylar eminence } \\
\text { pseudarthrosis }\end{array}$ & F3D-false negative \\
\hline \multirow[t]{2}{*}{6} & Lumbar pain & Zygapophyseal arthritis & No pathological uptake & Zygapophyseal arthritis & F3D-false negative \\
\hline & \multicolumn{5}{|c|}{ Discrepancy between xSPECT Bone ${ }^{\circledR}$ and diagnosis* } \\
\hline 7 & Left ankle pain & Tarsometatarsal arthritis & No pathological uptake & Fibromyalgia & xB-false positive \\
\hline 8 & Chronic left ankle pain & No pathological uptake & Calcaneus fracture & Fracture & xB-false negative \\
\hline 9 & Right hip pain, prosthesis & No pathological uptake & Hip uptake & Prosthesis failure & xB-false negative \\
\hline 10 & First tarsometatarsal pain & No pathological uptake & Tarsometatarsal uptake & Tarsometatarsal arthritis & xB-false negative \\
\hline 11 & Feet pain & $\begin{array}{l}\text { Micro fracture of the head } \\
\text { of the } 2 \text { nd metatarsal }\end{array}$ & $\begin{array}{l}\text { 2nd metatarso-phalangeal } \\
\text { joint uptake }\end{array}$ & Arthritis & xB-location \\
\hline 12 & Feet pain & $\begin{array}{l}\text { Micro fracture of } \\
\text { cuboid bone }\end{array}$ & No pathological uptake & $\begin{array}{l}\text { Spontaneous } \\
\text { disappearance of pain }\end{array}$ & xB-false positive \\
\hline 13 & Left scapula pain & Supraspinatus tendinopathy & No pathological uptake & $\begin{array}{l}\text { Spontaneous } \\
\text { disappearance of pain }\end{array}$ & xB-false positive \\
\hline 14 & Left ankle pain & No pathological uptake & Plantar fasciitis & Plantar fasciitis & xB-false negative \\
\hline 15 & Right wrist pain & Lunate bone fracture & $\begin{array}{l}\text { Lunate-capitate } \\
\text { bone conflict }\end{array}$ & Pseudarthrosis & xB-location \\
\hline \multirow[t]{2}{*}{16} & Distal left thumb pain & Osteitis of the last phalange & No pathological uptake & Conversion disorder & xB-false positive \\
\hline & \multicolumn{5}{|c|}{ Non-informative clinical and paraclinical follow-up } \\
\hline 17 & Left foot pain & Sesamoide bone contusion & Tarsometatarsal arthritis & & \\
\hline 18 & Left ankle pain & $\begin{array}{l}\text { Talocrural arthritis } \\
\text { with malleolus fracture }\end{array}$ & $\begin{array}{l}\text { Talocrural arthritis without } \\
\text { malleolus fracture }\end{array}$ & & \\
\hline 19 & Left ankle pain & Tibia fracture & Talocrural arthritis & & \\
\hline 20 & Right tibia pain & Talus fracture & No pathological uptake & & \\
\hline 21 & $\begin{array}{l}\text { Right first metatarsal } \\
\text { bone pain }\end{array}$ & $\begin{array}{l}\text { Sesamoide-metatarsal } \\
\text { bone conflict }\end{array}$ & $\begin{array}{l}\text { Fracture of the head of } \\
\text { the first metatarsal bone }\end{array}$ & & \\
\hline
\end{tabular}


should be noted that for four scans with concordant findings $\mathrm{xB}$ and $\mathrm{F} 3 \mathrm{D}$, follow-up was contradictory (three false negatives and one false positive results).

\section{Discussion}

The Siemens ${ }^{\circ} \mathrm{xB}$ tomographic image reconstruction is a new way of bone image reconstruction theoretically being suggested to provide better bone contrast, thus high-quality images compared with conventional reconstructions. This hypothesis should be assessed for confirmation. To our knowledge, this study is the first to evaluate the diagnostic reliability and accuracy of this novel reconstruction in routine clinical practice. The study includes a large number of patients and their follow-up and concludes to a high inter-observer agreement and a similar diagnostic confidence as compared with F3D.

A high kappa index for xB (0.89) [95\% CI 0.84-0.93] showed a very strong IOA, highlighting the reliability of interpretation, between junior and senior expert readers.

The kappa index obtained according to F3D reconstructions was also high (0.90) with a confidence interval [95\% CI 0.86-0.94] without statistically significant differences in inter-observer agreement. The same conclusions were obtained with the McNemar test $(p=0.532)$. We thus observed equivalent diagnostic confidence between $\mathrm{xB}$ and $\mathrm{F} 3 \mathrm{D}$ reconstructions.

Thirty-one IRDD (14.9\%) were observed among the 207 SPECT/CT. Of the 31 IRDD, 21 were classified as major (10.1\%). A diagnosis was made according to the follow-up in most IRDD cases $(16 / 21)$. With a better spatial resolution to observe smaller SPECT abnormalities and a better bone to soft tissue contrast, $\mathrm{xB}$ may theoretically allow increased detection and better visualization of weakly evolving or small abnormalities that could go unnoticed with F3D. However, according to our clinical experience, detecting smaller or weakly evolving abnormalities did not have a major clinical relevance and did not lead to a therapeutic modification.

Indeed, the higher the IRDD proportion, the higher is the IOD percentage (i.e., high IRDD $41.9 \%$ vs. low IRDD 19.8\%): borderline bone scan abnormalities were most likely interpreted subjectively (i.e., between physicians with different experience) and therefore more likely to induce IOD, with less clinical relevance.

Of the 16 IRDD, 10 diagnoses done by F3D vs. 6 by xB were confirmed through follow-up. This difference was explained in particular by a higher number of false positives for $\mathrm{xB}, 4$ against none for F3D (Fig. 2). However, the number of false negatives was almost equivalent, 5 for F3D and 4 for $\mathrm{xB}$ (Fig. 3). Finally, three radiopharmaceutical uptake errors were observed: two in $\mathrm{xB}$ and one in F3D. One radiopharmaceutical uptake error in $\mathrm{xB}$ was due to patient movements between the SPECT and the $\mathrm{CT}$ acquisitions (Fig. 4). These were not detectable on $\mathrm{xB} / \mathrm{CT}$ fused images alone but were detectable on $\mathrm{F} 3 \mathrm{D} /$ $\mathrm{CT}$ images. Aberrant $\mathrm{xB}$ images due to location uptake errors are easy to identify. However, when the movements are minimal, they can be undetectable and lead to diagnostic error. This suggests the necessity to systematically take a look at the F3D/CT slices in order to control the accurate registration of SPECT and CT slices in $\mathrm{xB}$ reconstruction. Nevertheless, the good spatial resolution of $\mathrm{xB}$ can ease the reading and thus change the diagnosis. This is illustrated in Fig. 5: a joint disorder was diagnosed between talus and trigonum bones using $\mathrm{xB}$ (and confirmed by follow-up) and as a talus contusion using F3D.

It should also be noted that the study was not carried out by comparing only the SPECT reconstructions but
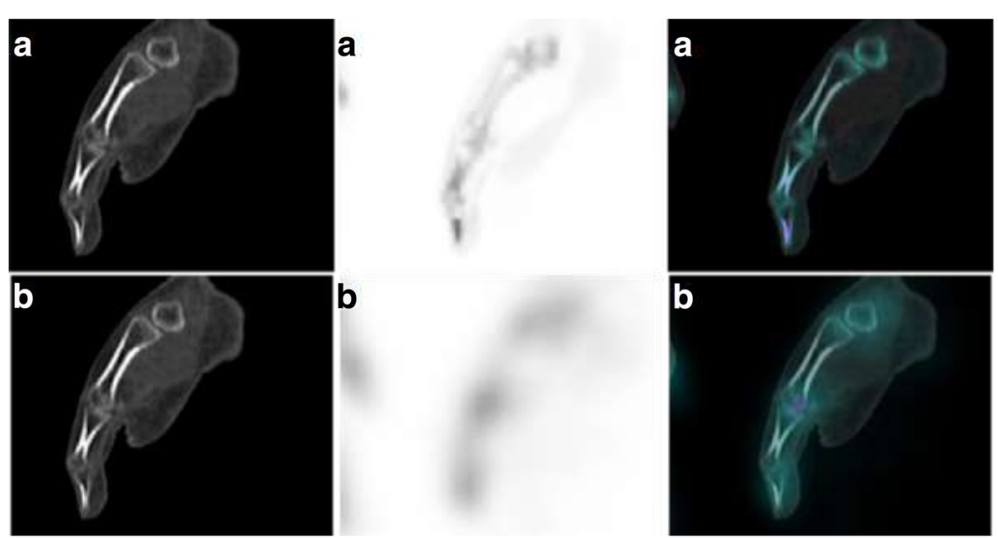

Fig. 2 Example of false positive of XSPECT Bone ${ }^{\oplus}$. This SPECT/CT was performed in order to explore a focal distal thumb pain persisting after a traumatism occurred several months ago. A moderate uptake involving only the last phalange of the thumb, higher than the other phalangeal uptakes, is observed on the $\mathrm{XB}$ image (a), matched with the focal pain and suggesting an osteitis. However, there is no pathological uptake on the F3D image (b). The MRI performed after SPECT/CT was normal and ruled out the osteitis. A conversion disorder was diagnosed 

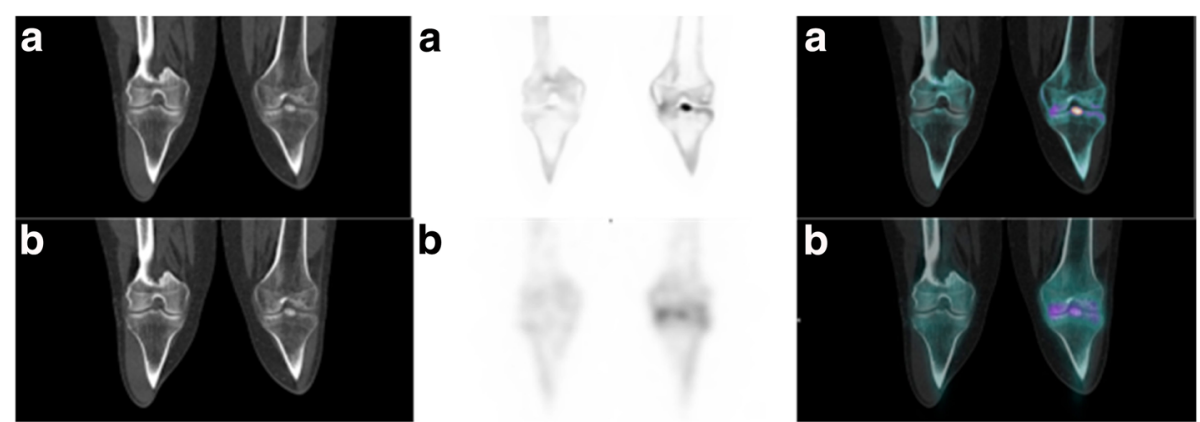

Fig. 3 Example of false negative of Flash $3 D^{\oplus}$. This SPECT/CT was performed in order to explore a left knee joint pain persisting after an intercondylar eminence fracture occurred several months ago. A focal intense uptake of the left intercondylar eminence is observed on the xB image (a) whereas a diffuse uptake of the tibiofemoral joint is observed on the F3D image (b). MRI realized after SPECT/CT confirmed the intercondylar eminence pseudarthrosis evoked on xB image

rather by comparing the registered images SPECT/CT with knowledge of the clinical context. The use of CT slices and the knowledge of pain mechanism may have an impact on the diagnostic confidence of the scintigraphy. Thereby, Vija et al. [13] demonstrated significantly higher accuracy of $x B$ used without CT slices compared to F3D. However, the difference was no longer statistically significant between the two reconstructions when fused with the CT slices.
Finally, the striking innovation of the $\mathrm{xB}$ reconstruction is the esthetic aspect of SPECT images, which could ease visualization and interpretation of anomalies on MIP images. This combined with clinical and paraclinical findings may enhance patient management and treatment.

Thus, the ease of interpretation provided by $\mathrm{xB}$ could bring an added value to the scintigraphic examination
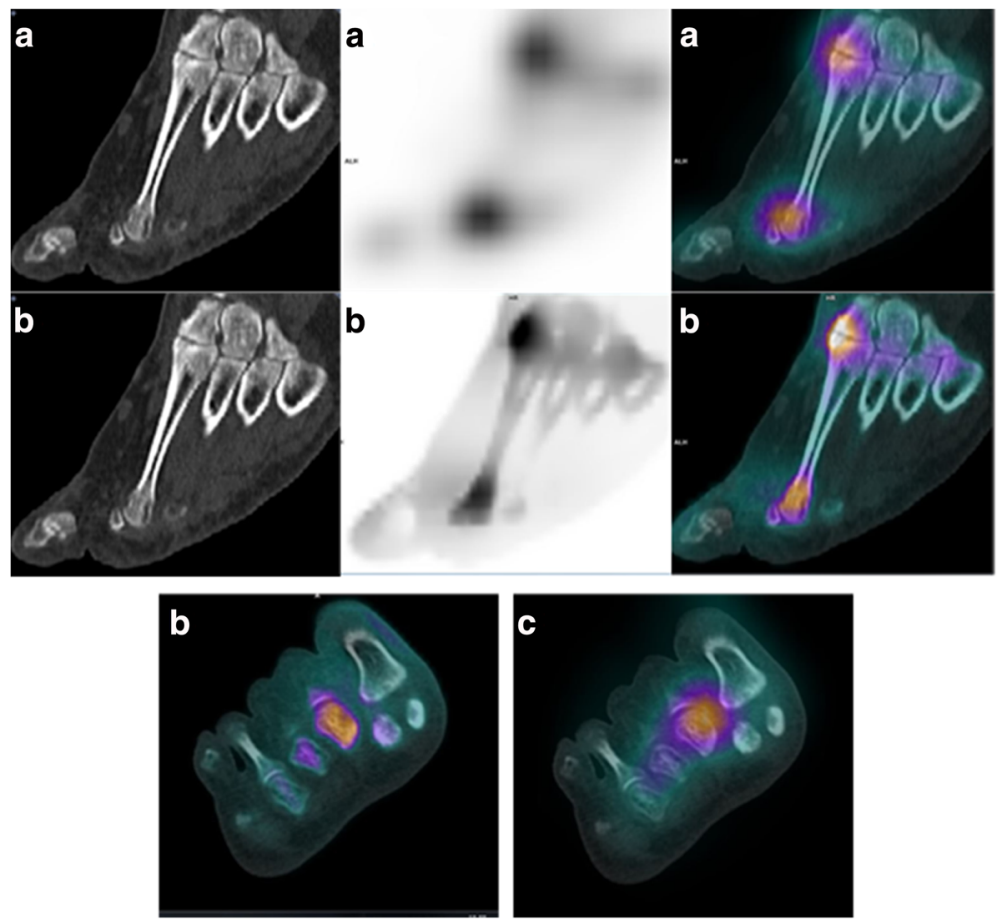

Fig. 4 Location error of XSPECT Bone ${ }^{\varpi}$ related to the movements between SPECT and CT acquisition. This SPECT/CT was performed in order to explore a foot pain with suspicion of complex regional pain syndrome. An uptake of the second metatarso-phalangeal joint is observed on the F3D image (a) whereas an uptake of the head of the second metatarsal is observed on the XB image (b). The absence of traumatic context and the evolution with painful flares for 2 years suggests an osteoarthritic origin, confirming the hypothesis evoked by F3D/CT. Moreover, we can observe on the axial slice F3D/CT (c) a spatial shift between F3D acquisition and CT acquisition related to the movements of the patient, causing a bad reconstruction and a localization error of $\mathrm{XB}$ 

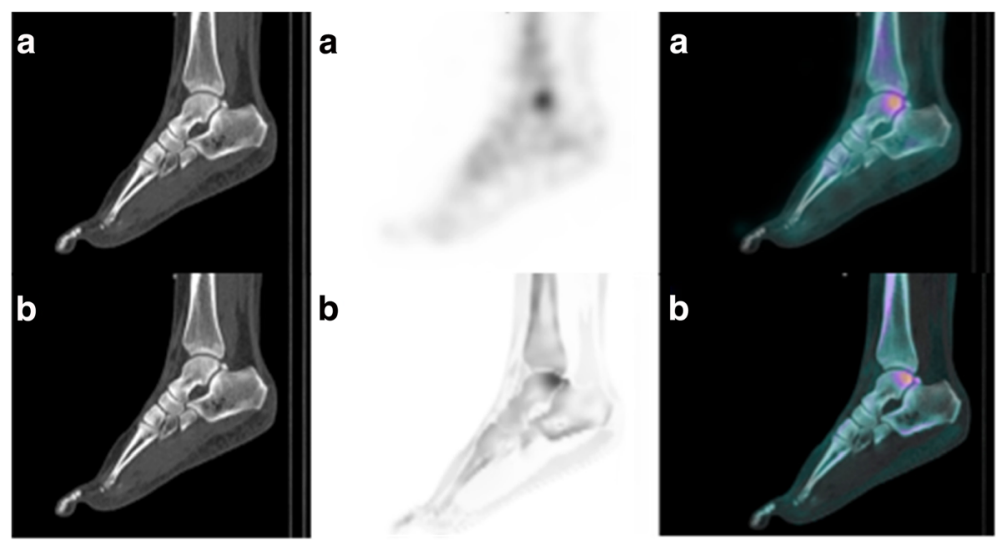

Fig. 5 Example of a better location of a pathological uptake with XSPECT Bone ${ }^{\varpi}$ reconstruction. This SPECT/CT was performed in order to explore a chronic right ankle pain which appeared 1 year ago without traumatism. An uptake of the talus is observed on the F3D image (a) whereas an uptake of the talus and of a trigonum bone is observed on the XB image (b). MRI realized after SPECT/CT did not show contusion of the talus but confirmed the right os trigonum syndrome observed on $x B$ image

given the resultant high-quality images. Most clinicians pay close attention to the images and this often without reading the acquisition report [14].

Given the technological advancement in bone scintigraphy, clinicians and health care provider's objectives are to highlight diagnostic confidence thus limiting the use of additional imagery.

All together, we believe that prospective studies are warranted to reach more conclusive results in regard with $\mathrm{xB}$ reconstruction reliability and accuracy in bone imaging. This further step can help at reaching robust clinical evidence as well as diagnostic consensus.

Similarly, to repeat this study in a multicentric way would limit the interpretation bias observed in our study. Our diagnostic decisions were not independent given that the junior physician was trained by the senior physician from our nuclear medicine department. Nevertheless, the inter-observer agreement scores are comparable to those observed in the literature $(0.87-0.97)[8,15-18]$.

\section{Conclusions}

Our study demonstrated that $\mathrm{xB}$ reconstruction algorithm was a reliable tool in diagnosis of non-oncological bone diseases, providing high inter-observer agreement and similar diagnostic confidence compared with F3D. Moreover, it may improve SPECT/CT images quality thanks to a striking esthetic aspect. Moreover, the proper registration between SPECT and CT slices needs to be checked systematically in F3D images.

\section{Funding}

None.

\section{Authors' contributions}

The principal investigators were OD and SQ. They performed the interpretations of all bone scintigraphy and the redaction of the manuscript and its submission. MG performed the statistical analysis. DB helped us with the technical aspect of the reconstruction algorithm. PYS, RA, ALD-P, PYLR, and PR helped us imagine the design of our study and improve it. ZA revised and wrote the intellectual content of the manuscript and helped at data and result interpretation. All authors read and approved the final manuscript.

Ethics approval and consent to participate

At the time of the study, in France, no approval by an ethics committee was required for retrospective studies. All patients gave written informed consent for the scientific use of their data.

Consent for publication

All patients included gave written informed consent that their data could be used for scientific purposes.

\section{Competing interests}

The authors declare that they have no competing interests.

\section{Publisher's Note}

Springer Nature remains neutral with regard to jurisdictional claims in published maps and institutional affiliations.

\section{Author details}

${ }^{1}$ Nuclear Medicine Department, CHRU Hospital Morvan, Brest, France. ${ }^{2} \mathrm{CHRU}$ Brest, Brest, France. ${ }^{3}$ Service de Médecine Nucléaire, EA 3878 GETBO IFR 148, Brest, France. ${ }^{4}$ Université de Bretagne Occidentale, Brest, France. ${ }^{5}$ Brest Medical University Hospital-Inserm CIC 1412, Brest, France. ${ }^{6}$ Nuclear Medicine Department, University Hospital, Boulevard Tanguy Prigent, 29200 Brest, France.

Received: 6 November 2017 Accepted: 31 January 2018

Published online: 12 February 2018

\section{References}

1. Vija H. Introduction to XSPECT* technology: evolving multi-modal SPECT to become context-based and quantitative. Siemens Med Solut USA. 2013.

2. Ghosh P. XSPECT: a clinical overview. Siemens Med Solut USA.

3. Savelli G, Maffioli L, Maccauro M, De Deckere E, Bombardieri E. Bone scintigraphy and the added value of SPECT (single photon emission tomography) in detecting skeletal lesions. Q J Nucl Med. 2001;45:27-37.

4. Even-Sapir E, Metser U, Mishani E, Lievshitz G, Lerman H, Leibovitch I. The detection of bone metastases in patients with high-risk prostate cancer: 99mTc-MDP planar bone scintigraphy, single- and multi-field-of-view SPECT, 18F-fluoride PET, and 18F-fluoride PET/CT. J Nucl Med. 2006;47:287-97. 
5. Bryant LR, Song WS, Banks KP, Bui-Mansfield LT, Bradley YC. Comparison of planar scintigraphy alone and with SPECT for the initial evaluation of femoral neck stress fracture. AJR Am J Roentgenol. 2008;191:1010-5.

6. Horger M, Eschmann SM, Pfannenberg C, Vonthein R, Besenfelder H, Claussen $C D$, et al. Evaluation of combined transmission and emission tomography for classification of skeletal lesions. AJR Am J Roentgenol. 2004;183:655-61.

7. Utsunomiya D, Shiraishi S, Imuta M, Tomigushi S, Kawanaka K, Awai K, et al. Added value of SPECT/CT fusion in assessing suspected bone metastasis: comparison with scintigraphy alone and nonfused scintigraphy and CT. Radiology. 2006;238:264-71.

8. Huellner MW, Burkert A, Strobel K, Perez Lago Mdel S, Werner L, Hug U, et al. Imaging non-specific wrist pain: interobserver agreement and diagnostic accuracy of SPECT/CT, MRI, CT, bone scan and plain radiographs. PLoS One. 2013;8:e85359.

9. Even-Sapir E, Flusser G, Lerman H, Lievshitz G, Metser U. SPECT/multislice low-dose CT: a clinically relevant constituent in the imaging algorithm of nononcologic patients referred for bone scintigraphy. J Nucl Med. 2007;48: $319-24$

10. Zhao Z, Li L, Li F, Zhao L. Single photon emission computed tomography/ spiral computed tomography fusion imaging for the diagnosis of bone metastasis in patients with known cancer. Skelet Radiol. 2010;39:147-53.

11. Romer W, Nomayr A, Uder M, Bautz W, Kuwert T. SPECT-guided CT for evaluating foci of increased bone metabolism classified as indeterminate on SPECT in cancer patients. J Nucl Med. 2006:47:1102-6.

12. Van den Wyngaert T, Strobel K, Kampen WU, Kuwert T, van der Bruggen W, Mohan HK, et al. The EANM practice guidelines for bone scintigraphy. Eur J Nucl Med Mol Imaging. 2016;43:1723-38.

13. Vija AH, Ma J, Bartenstein P, Froelich J, Kuwert T, Macapinlac H, et al. ROC analysis for XSPECT bone. J Nucl Med. 2015;56(supplement 3):1279.

14. Bonardel G, Mantzarides M, Brenot-Rossi I, Gibold C, Foulquie P, Zerdoud S, et al. Enquête nationale de satisfaction réalisée auprès des cliniciens prescripteurs concernant la forme des comptes rendus en médecine nucléaire. Med Nucl. 2008:32:482-7.

15. Girma A, Ramadan A, Benisvy D, Malek Z, Fontana X, Darcourt J, et al. Reproductibilité en scintigraphie osseuse planaire, TEMP et TEMP/TDM du pied douloureux: importance d'une sémiologie standardisée. Med Nucl. 2010;34:513-27.

16. Zhang Y, Shi H, Gu Y, Xiu Y, Li B, Zhu W, et al. Differential diagnostic value of single-photon emission computed tomography/spiral computed tomography with Tc-99m-methylene diphosphonate in patients with spinal lesions. Nucl Med Commun. 2011;32:1194-200.

17. Pagenstert Gl, Barg A, Leumann AG, Rasch H, Müller-Brand J, Hintermann B, et al. SPECT-CT imaging in degenerative joint disease of the foot and ankle. J Bone Joint Surg Br. 2009;91:1191-6.

18. Helyar V, Mohan HK, Barwick T, Livieratos L, Gnanasegaran G, Clarke SE, et al. The added value of multislice SPECT/CT in patients with equivocal bony metastasis from carcinoma of the prostate. Eur J Nucl Med Mol Imaging 2010;37:706-13.

\section{Submit your manuscript to a SpringerOpen ${ }^{\circ}$ journal and benefit from:}

- Convenient online submission

- Rigorous peer review

- Open access: articles freely available online

- High visibility within the field

- Retaining the copyright to your article 